\title{
UDR e TFP: a força bruta que enterrou a reforma agrária na constituinte de 1987
}

\section{UDR and TFP: the raw power buried Agrarian Reform in Constituent of 1987}

\author{
Luiz Otávio Ribas \\ Mestre em "Filosofia e Teoria do Direito" (Universidade Federal de Santa Catarina - UFSC) \\ Professor do Centro Universitário Curitiba (UNICURITIBA) \\ luizotavioribas@hotmail.com
}

\begin{abstract}
Resumo
A Assembléia Nacional Constituinte (ANC) de 1987, por sua Subcomissão da Política Agrária e Fundiária e da Reforma Agrária, deixou um capítulo funesto para a história do direito brasileiro, amplamente ignorado nas obras jurídicas dogmáticas que abordam o tema. Essa comissão foi marcada por dribles no regimento e favorecimentos de grupos políticos que apoiavam o regime ditatorial. Trata-se de questionar se esse episódio influenciou uma norma antidemocrática ou se significa um passo para o estado de exceção, em função do totalitarismo que baseou a decisão de sua instauração. Para tanto, traz-se a contribuição de Giorgio Agamben, dos conceitos de poder constituinte e constituído. Analisam-se dois sujeitos decisivos para a derrota da Reforma Agrária na constituinte e nos anos seguintes: a União Democrática Ruralista (UDR) e a Sociedade Brasileira de Defesa da "Tradição, Família e Propriedade" (TFP). Por fim, abrangem-se justamente os efeitos jurídicos e sociais desse processo no contexto pós1988.
\end{abstract}

Palavras-chave: Sociologia do Direito no Brasil. Constituinte de 1987. Estado de Exceção. Reforma Agrária. Subjetividade.

\begin{abstract}
The National Constitutional Assembly in 1987 by its Subcommittee on Agrarian Policy and Land and Agrarian Reform, made a fateful chapter in the history of Brazilian law, largely ignored in legal dogmatic works that address. This commission has been marked by cronyism and dribbling in the regiment of political groups that supported the dictatorship. It is questionable whether this episode has influenced an undemocratic rule or whether it means a step in the state of exception, depending on the totalitarianism he based the decision on its establishment. To do so, brings the contribution of Giorgio Agamben, the concepts of constituent and constituted power. It examines two subjects that were decisive in the defeat of Agrarian Reform in the constituent assembly and in the years that followed: the Rural Democratic Union (UDR) and the Brazilian Society for the Defense of "Tradition, Family and Property (TFP). Finally, just to cover the legal and social aspects of this process in the post-1988.
\end{abstract}

Keywords: Sociology of Brazilian Law. Constituent Assembly 1987. State of Exception. Agrarian Reform. Subjectivity.

Originais recebidos em: 18/11/2010

Aceito para publicação em: 25/11/2010

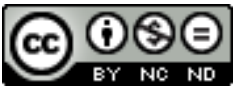

Este trabalho está licenciado sob uma Licença Creative Commons Atribuição-Uso NãoComercial-Vedada a criação de obras derivadas 3.0 Unported License. 


\section{Introdução}

A constituinte de 1987 no Brasil foi instaurada a partir da decisão do próprio corpo legislativo eleito "democraticamente" e sem mandato para composição da nova constituição. $\mathrm{O}$ argumento político utilizado pelos deputados, dentre outros, foi o receio de que as forças políticas ditatoriais retornassem ao poder, com o pretexto de controlar a “agitação" provocada por uma eleição para deputados constituintes. Os conturbados embates ocorridos no processo constituinte colocam em xeque essa opção, principalmente, no que tange à reforma agrária. Alguns setores conservadores, e até mesmo de espectro totalitários, da sociedade civil organizada, sobrepuseram os seus interesses de classe e foram os grandes vitoriosos.

Recontar esse breve histórico dos bastidores da constituinte de 1987 no que tange à reforma agrária significa recuperar um dos capítulos mais funestos da história do direito no Brasil. Foi quando vivemos um período ditatorial que estendeu seus efeitos muito tempo depois do seu "comemorado" final em 1985, inclusive fazendo-se sentir até os dias de hoje, por exemplo, com as discussões sobre a recuperação da memória histórica da perseguição aos revoltosos e insurgentes, anistiados junto com seus algozes.

Aqui se analisa, a partir da filosofia do direito, as categorias de direito, política e estado de exceção, para compreender como que no Brasil a exceção sobrepôs-se como espaço único e destruidor de toda a política para o meio rural. A reforma agrária tornouse motivo de preocupação para os proprietários rurais e este receio tornou-se desculpa para todo o tipo de ação e imposição de vontade por meio do aparato estatal e da lei.

Uma das razões para este tema está com Hannah Arendt, que levanta a dúvida de que a aparente normalidade após um regime totalitário tratar-se-ia provavelmente de um novo colapso moral (Arendt, 2004, p.108). Podemos comparar essa dúvida com a aparente normalidade após o regime de ditadura militar no Brasil (1964-1985).

Outra questão envolve o Direito e a civilização, Sigmund Freud diz que

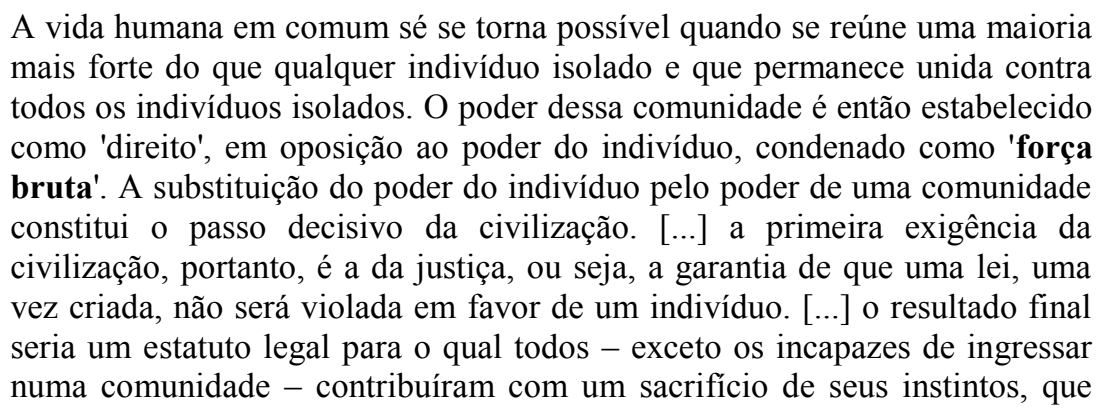


não deixa ninguém - novamente com a mesma exceção - à mercê da força bruta. [...] a liberdade do indivíduo não constitui um dom da civilização. (Freud, 1997, p. 49).

Demonstrar-se-á que a atuação autoritária da União Democrática Ruralista (UDR) e da Sociedade Brasileira de Defesa da "Tradição, Família e Propriedade" (TFP) condizem como exemplos para o que Freud qualifica de "força bruta", e "incapazes de ingressar numa comunidade", inclusive colocando à prova nossa aparente normalidade e a contribuição "civilizatória" de nossa constituição federal, uma vez que foi justamente em nome destes sujeitos que "instaurou-se" a lei constitucional em relação à política agrária.

Ademais, o contexto político da época envolvia grande mobilização popular em relação ao processo de redemocratização, enquanto que na cúpula de Brasília continuavam as mesmas negociatas e bravatas. Grande parte do Congresso Nacional era formada por "cães de guarda" da ditadura e outras forças conservadoras e reacionárias. Parte da juventude brasileira ainda estava anestesiada depois de tanta truculência, perseguições e "lições de moral e cívica" 1 .

Assim, o episódio da Subcomissão da Política Agrária e Fundiária e da Reforma Agrária será contado a partir do embate entre duas classes políticas antagônicas, os grandes proprietários de terra e os trabalhadores rurais. $\mathrm{O}$ conchavo dos latifundiários com os deputados constituintes ficou notabilizado como um dos maiores da Assembléia Nacional Constituinte de 1987. Porém, a truculência dos membros da UDR e o desrespeito dos deputados com o regimento não ficaram marcados na memória recente dos brasileiros. Recuperá-la é o objetivo maior deste texto.

\section{Os embates na subcomissão de reforma agrária}

Para melhor entendimento, apresentar-se-á visões históricas construídas a partir de testemunhos de sujeitos que estiveram envolvidos diretamente com os trabalhos na constituinte. A finalidade é dar voz a versões bastante distintas daquelas tradicionais e comemorativas de todo o processo de redemocratização no país.

Primeiramente, parte-se da idéia de Thomaz Miguel Pressburger, de que a Constituição, na sociedade capitalista, representa o papel de formalizar os conflitos,

${ }^{1} \mathrm{O}$ principal manual utilizado nas escolas brasileiras foi: Xavier Teles, Antônio. Educação moral e cívica: introdução à cidadania. 7. ed. São Paulo: Nacional, 1974. Importante notar que no capítulo sobre a "Democracia brasileira" está o seguinte ensinamento: “'Democracia', definida teoricamente, é algo diferente da realidade vivida". (1974: 117). Que a história não os culpe pela sua sinceridade.

Em Debat: Rev. Dig., ISSNe 1980-3532, Florianópolis, n. 5, p. 1-15, 2011. 
desligando-os das contradições de classe, ao mesmo tempo em que "a Constituição é também o reflexo do grau de organização e conquistas das diversas forças que compõem a sociedade". Assim, a "representação jurídica das relações conflitivas favorece a imagem do Estado que, por se utilizar de normas e regras previamente estabelecidas, se apresenta como uma forma política consensual. Ou seja, desligada e acima das classes sociais" (Pressburger, 1986, p. 04-05). O objetivo é justamente analisar parte da organização das forças políticas do período referido, notadamente, a UDR e a TFP.

José Gomes da Silva, que foi um dos teóricos do Direito Agrário brasileiro que participaram das discussões na Subcomissão da Política Agrária e Fundiária e Reforma Agrária, afirma que o confronto que estava representado na ocasião era "a briga dos sem-terra contra os com-bala". A luta constitucional envolveu os trabalhos da Assembléia Nacional Constituinte (ANC), nas etapas da Comissão de Ordem Econômica, da Comissão de Sistematização e do Plenário, conflitos paralelos acontecidos em galerias, bastidores, na Praça dos Três Poderes e em diversos outros campos (Gomes da Silva, 1989, p. 53).

Segundo Adriano Pilati, a proposta inicial apresentada pela Campanha Nacional pela Reforma Agrária (CNRA) ${ }^{2}$ incomodou bastante, isso porque propunha: subordinação do direito de propriedade a uma obrigação social; estabelecimento de limite máximo para a propriedade privada e; imissão imediata da União na posse do imóvel desapropriado (Pilati, 1988, p. 142-143).

Para um dos autores desta proposta, representante da Comissão Pastoral da Terra (CPT), Hamilton Pereira da Silva, a violência é "filha do monopólio da terra, filha do latifúndio, numa situação em que nem Estado nem latifúndio reconhecem o direito à cidadania, não reconhecem sequer o direito à vida" (apud Gomes da Silva, 1988, p. 61).

Plínio de Arruda Sampaio, na ocasião da apresentação da proposta dos movimentos populares aos constituintes disse que "os homens esquecem mais depressa a morte de seu pai do que a perda do seu patrimônio"; e "não há coisa mais difícil, nem êxito mais duvidoso, nem mais perigoso, do que o estabelecimento de novas leis". Para ele, “o novo Legislador terá por inimigos todos aqueles a quem as leis antigas beneficiavam, e tímidos defensores nos que foram beneficiados pelo novo estado de

${ }^{2}$ A CNRA congregava: CONTAG, CUT, MST, CNBB, CIMI, CPT, Pastoral Operária, Diocese de Goiás Velho, ABRA, IBASE; mais MIRAD, INCRA, entre outros. Contra a reforma agrária posicionaram-se UDR, CNA, OCB, TFP, SRB, entre outros.

Em Debat: Rev. Dig., ISSNe 1980-3532, Florianópolis, n. 5, p. 1-15, 2011. 
coisas" (apud Gomes da Silva, 1988, p. 58). Uma excelente descrição do que estaria por vir.

A partir desse debate inicial, percebe-se que a questão central referia-se à tentativa de limitação do direito de propriedade privada da terra rural. Importante referir que a realidade rural brasileira era, e continua sendo, de uma das maiores em concentração de terra no mundo.

A principal discussão da subcomissão iniciou em 23 de maio de 1987, para debate da proposta, que dentre outras questões, decidia sobre o uso da expressão "obrigação social" ou "função social". Foi quando o presidente da reunião, senador Edison Lobão (PFL-MA) invocou o art. 40 do Regimento Interno que permite a presença de qualquer pessoa para assistir às sessões das galerias, desde que desarmada e guarde silêncio. $\mathrm{Na}$ ocasião foram apreendidas 50 armas, que eram portadas pelos visitantes nas galerias ${ }^{3}$ (Gomes da Silva, 1988, p. 76).

Esse fato corrobora com a afirmação de que tratava-se de uma disputa entre os sem-terra e os com-bala. Em outros termos, um estágio de reconstrução da legitimidade do poder estatal que estava a ser recomposto "democraticamente", mas para alguns a partir do "argumento" de uma arma de fogo.

Em seguida foi debatida a apresentação de emenda que substituía integralmente o projeto apresentado pelo relator, ato vedado pelo regimento, na interpretação da deputada Irma Passoni (PT-SP). O artigo do regimento que tratava da questão estava redigido da seguinte maneira: "Fica vedada a apresentação de Emenda que substitua integralmente o projeto ou que diga respeito a mais de um dispositivo". Não obstante a argumentação e a clareza do dispositivo, o presidente da sessão indeferiu a questão de ordem e autorizou a discussão da Emenda. Em nenhuma das outras 24 Subcomissões existentes na constituinte foi admitida emenda substitutiva, somente nesta (Gomes da Silva, 1988, p. 76-79).

Tratava-se do substitutivo Rosa Prata (PMDB-MG) que: garantia o direito de propriedade rural e o cumprimento de uma função social aparecia como mera recomendação; a função social seria preenchida com o cumprimento de apenas um dos quatro requisitos; ${ }^{4}$ eliminava a área máxima para a propriedade rural privada; permitia a

\footnotetext{
${ }^{3} \mathrm{O}$ autor não esclarece quem eram os portadores destas armas, mas sabe-se que o plenário estava repleto de representantes da sociedade civil, inclusive ligados à UDR. Em seguida, o mesmo autor relata atos hostis e violentos desses sujeitos durante as discussões da Subcomissão.

${ }^{4}$ Vale destacar a referência de Thomaz Miguel Pressburger de que a partir da Constituição de 1934, apareceu o conceito de "função social" ou "interesse social ou coletivo". Mas que "em TODAS as Constituições a interpretação

Em Debat: Rev. Dig., ISSNe 1980-3532, Florianópolis, n. 5, p. 1-15, 2011.
} 
desapropriação apenas de propriedade "improdutiva" a ser definida em lei, com indenização em títulos para as terras e em dinheiro para as benfeitorias; eliminava a imissão imediata da União na posse do imóvel desapropriado, assegurando ao proprietário plena defesa judicial (Pilati, 1988, p. 144-145).

Durante o intervalo das sessões alguns deputados foram ameaçados de morte, houve tentativas de suborno, objetos foram arremessados contra deputados, muitas pessoas entraram armadas na galeria, apesar da ordem do presidente. Membros da UDR nas galerias lançavam objetos contra os deputados (Gomes da Silva, 1988, p. 80-81).

Mas isso não foi tudo, Gomes da Silva relata que:

Vaias, aplausos, trompaços, gravatas, espancamentos e objetos atirados pelos membros da UDR, agressões até a jornalistas e outras violências não agitaram tanto os trabalhos da Subcomissão quanto o desaparecimento do deputado Benedicto Monteiro (PMDB-PA) na hora da votação decisiva do pedido de destaque para o Substitutivo Rosa Prata. Como se viu [...] essa ausência permitiu a manobra do presidente da Subcomissão, senador Edison Lobão (PFL-MA), que derrubou o Anteprojeto do Relator, deputado Oswaldo Lima Filho (PMDB-PE) (1988, p. 84).

O deputado Benedicto Monteiro sumiu no momento decisivo. Encontrado em Belém (PA), foi fretado um jatinho para trazê-lo de volta a Brasília, onde chegou ao Congresso às três horas da madrugada, suficiente apenas para votar em pequenos destaques do relator que eliminavam alguns absurdos feitos com o projeto. Até hoje não se sabe exatamente o que ocorreu com o constituinte. Algumas versões dizem que ele foi seqüestrado, outras que foi subornado, outras trabalham com a hipótese de problemas de saúde. Assim "com sequestro ou não, rasgado ou cumprido o Regimento, Ulysses crucificado ou redimido, a grande vítima foi a Reforma Agrária e prejudicados, como sempre, foram os trabalhadores rurais" (Gomes da Silva, 1988, p. 86).

Gomes da Silva refere-se a uma manobra parlamentar espúria do presidente da ANC Ulysses Guimarães, que orientou a decisão de Edison Lobão no voto do suplente do deputado Benedicto Monteiro (PMDB-PA). Por meio de um ofício, Ulysses Guimarães ordenou a Edison Lobão que conferisse a suplência do constituinte do PMDB ao PL, contrariando o regimento. Era justamente o voto que faltava para aprovar o substitutivo Rosa Prata, invertendo-se o resultado da votação decisiva (1988, p. 5466).

do que seja isso, foi remetida para leis especiais que, ou não foram feitas, ou então a coisa foi reinterpretada de forma contrária à própria função ou interesse social" (Pressburger, 1986, p. 19). 
As manobras estatutárias de Lobão e Ulysses ocorreram por influência de forças políticas que não tinham mandato constituinte. O deputado Percival Muniz (PC do BMT) na época denunciou a ação de Ronaldo Caiado de Castro, presidente da UDR.

É válido referir que a investida violenta das forças políticas dos com-bala aos sem-terra, como já era de se esperar, perpetuou-se após a promulgação da Constituição. Conforme Muniz, "éramos acusados de subversivos porque pichávamos muros exigindo diretas já, anistia ou, então, que a Amazônia fosse respeitada", enquanto que os membros da UDR que se armavam, pagavam jagunços, contratavam pessoas para participar de milícias particulares, não eram considerados subversivos (Muniz apud Gomes da Silva, 1988, p. 72-73).

Ao final, ficou evidente a todos (imprensa, classe política, setores adversários), “o poder de veto exercido pela UDR durante o primeiro turno de votações em plenário, e em reconhecê-la como grande vitoriosa na decisão constitucional sobre a Reforma Agrária”. Ronaldo Caiado, o Presidente da UDR na época, recebeu o resultado como uma vitória sua e provocou seus adversários: “a esquerda é tão infantil e incompetente que, se não existisse, teríamos de criá-la. Subestimaram nossa capacidade e isso nos deu a vitória. Essa votação vai entrar nos momentos históricos da UDR” (Pilati, 1988, p. 147-202).

Conforme Pilati, a UDR conseguiu mobilizar massas para compor o quadro inquietante que transformou "a Constituinte em um palco do conservadorismo, impedindo a realização das 'mudanças' e colocando dúvidas sobre o desfecho do processo de redemocratização". A possibilidade de influência de grupos como a UDR foi possível "pelas crises decorrentes das próprias características do regime autoritário precedente", a transição para a democracia foi "marcada pela alta capacidade de influência e controle sobre ela, reveladas pelos atores autoritários” (1988, p. 203-210).

Em outras palavras, para Gomes da Silva, neste dia, os parlamentares conservadores e a UDR enterraram a Reforma Agrária (1988, p. 83).

Para Jacques Alfonsin, os efeitos jurídicos concretos que resultaram desses fatos foram aumentar os problemas que visavam solucionar, "acentuando injustiças seculares que marcam a violação dos direitos humanos fundamentais dos sem-terra em nosso país", reflexo da origem tão vergonhosa e alheia ao "poder originário do povo" de alguns constituintes. Com isso se obteve um "lastro textual de lei de extraordinário apelo ideológico e publicitário contrário a qualquer mudança" (Alfonsin, 2003, p. 213). 
Para seguir na análise desses efeitos traz-se alguns dados sobre os conflitos no campo após 1988 (COMISSÃO PASTORAL DA TERRA, 1998, p. 16) ${ }^{5}$ :

\begin{tabular}{|c|c|c|c|c|c|c|c|c|c|c|c|}
\hline Formas de violência & 1988 & 1989 & 1990 & 1991 & 1992 & 1993 & 1994 & 1995 & 1996 & 1997 & $\begin{array}{l}\text { Taxa de cresci- } \\
\text { mento linear a/a }\end{array}$ \\
\hline Expulsão (1) & 3.932 & 1.842 & 1.681 & 413 & 1.664 & 1.369 & 388 & 1.146 & 270 & 304 & $-7,1983$ \\
\hline Despejo jurídico (1) & 2.387 & 3.107 & 2.544 & 2.286 & 6.001 & 12.469 & 17.687 & 12.832 & 17.595 & 17.070 & 85,736 \\
\hline $\begin{array}{l}\text { Ameaça de } \\
\text { expulsão (1) }\end{array}$ & 3.402 & 3.055 & 7.690 & 7.931 & 2.090 & 5.234 & 4.535 & 2.114 & 2.923 & 720 & $-10,686$ \\
\hline $\begin{array}{l}\text { Destruição de casas } \\
\text { (1) }\end{array}$ & 132 & 306 & 852 & 749 & 703 & 667 & 1.901 & 1.112 & 1.337 & 2.624 & 157,78 \\
\hline $\begin{array}{l}\text { Destruição de roças } \\
\text { (1) }\end{array}$ & 1.024 & 300 & 1.175 & 1.280 & 1.040 & 1.419 & 5.239 & 1.589 & 3.677 & 1.307 & 23,977 \\
\hline Assassinatos (2) & 93 & 56 & 75 & 49 & 46 & 52 & 47 & 41 & 54 & 30 & $-4,8941$ \\
\hline $\begin{array}{l}\text { Tentativa s de } \\
\text { Assassinato (2) }\end{array}$ & 68 & 100 & 80 & 96 & 47 & 37 & 62 & 43 & 71 & 37 & $-6,943$ \\
\hline Ameaça de morte (2) & 153 & 134 & 190 & 253 & 164 & 154 & 212 & 155 & 88 & 92 & $-4,6702$ \\
\hline $\begin{array}{l}\text { Agredidos fisicamente } \\
\text { (2) }\end{array}$ & 288 & 1.079 & 3.348 & 1.691 & 1.379 & 1.080 & 1.017 & 2.010 & 124 & 640 & $-26,364$ \\
\hline Lesões corporais (2) & 153 & 512 & 130 & 5 & 91 & 2.048 & 151 & 528 & 220 & 109 & 7,7045 \\
\hline Torturados (2) & 6 & 66 & 25 & 166 & 15 & 87 & 39 & 72 & 12 & 5 & $-46,566$ \\
\hline Presos (2) & 267 & 401 & 192 & 261 & 304 & 272 & 333 & 833 & 198 & 381 & 6,7961 \\
\hline $\begin{array}{l}\text { Índice de violência } \\
\text { no campo }\end{array}$ & 11.905 & 9.116 & 17.982 & 15.180 & 13.544 & 24.888 & 31.611 & 22.475 & 26.569 & 23.319 & 15,023 \\
\hline
\end{tabular}

(1) Violência contra posse e propriedade - patrimônio,

(2) Violência contra pessoa.

Obs: Todas as variáveis identificadas com (1) os valores tem por unidade número de famílias. As variáveis identificadas com (2) os valores tem por unidade números.

Fonte: CPT (vários anos)

A partir destes dados, a Comissão Pastoral da Terra concluiu que houve uma transferência da violência ilegítima da expulsão e ameaça de expulsão por parte de agentes privados, para o despejo jurídico, ou violência legitimada, sem que houvesse a redução nos índices de violência geral, pelo contrário, houve aumento da violência no campo. As principais formas de violência referidas foram a destruição de casas e o despejo jurídico (Comissão Pastoral da Terra, 1998, p. 15). Concluíram que:

\footnotetext{
${ }^{5}$ Alguns depoimentos sobre essa questão no período anterior a 1988 encontram-se em: CONSELHO FEDERAL DA OAB. Violência no campo. Rio de Janeiro: Folha Carioca, 1987.
}

Em Debat: Rev. Dig., ISSNe 1980-3532, Florianópolis, n. 5, p. 1-15, 2011. 
Tudo indica que o aumento da violência legítima, em parte, está relacionado ao aumento da ocupação de terra por parte dos movimentos dos sem-terra. Como conseqüência, por um lado, o movimento acaba disputando juridicamente a terra com os proprietários (violência contra o patrimônio despejo jurídico) e; por outro lado, os órgãos de repressão passaram a atuar de maneira mais intensiva contra os elementos sem-terra (violência contra a pessoa-prisões).

As ações governamentais objetivando os assentamentos sempre estão atreladas às pressões dos movimentos dos sem-terra através de suas ocupações; e que o aumento do número de famílias assentadas pelos órgãos públicos contribui na diminuição da violência no campo (1998, p. 15-17).

Percebe-se que a Reforma Agrária ficou comprometida com as decisões dos constituintes, baseadas na ação bem sucedida de atores conservadores e autoritários. Antes de tirar outras conclusões, é necessário aprofundar a análise desses sujeitos, com a apresentação de campanhas de propaganda da TFP.

\section{Propaganda contra a reforma agrária}

Neste ponto traz-se à análise a propaganda contra a Reforma Agrária que foi veiculada pela Sociedade Brasileira de Defesa da "Tradição, Família e Propriedade" (TFP): no período da constituinte, por meio de um parecer sobre a situação agrária brasileira; ${ }^{6}$ no período seguinte à promulgação da constituição, um panfleto que buscava instruir os proprietários rurais a prevenirem as invasões por grupos de sem-terra. ${ }^{7}$

Em ambos os documentos caracteriza-se de forma cristalina um grupo com tinta totalitária, chegando a aproximar-se do fascismo, com sua campanha anticomunistas e anti-sem-terras. Fica claro que buscam a eliminação, inclusive física, desses sujeitos.

No ano de 1987 circularam entre os deputados e senadores integrantes da Constituinte materiais produzidos pela TFP, que tinham a função de sugerir subsídios para os debates. A entidade produziu os textos tendo em vista a crescente preocupação dos proprietários rurais com supostas ameaças à livre iniciativa e à propriedade privada no curso dos trabalhos da Assembléia Nacional Constituinte. Principalmente, diante do "problema" da Reforma Agrária. Num dos panfletos consta que a defesa dessas bandeiras fazem parte de uma "verdadeira cruzada" da entidade desde a década de 1960, no início da ditadura militar. A TFP distribuiu a todos os componentes da Subcomissão

\footnotetext{
6 Faoro, Atilio Guilherme. Reforma Agrária: terra prometida, favela rural ou 'kolkhozes'?. São Paulo: Vera Cruz, 1987.

${ }^{7}$ Comissão de Estudos Agrários da Sociedade Brasileira de Defesa da Tradição, Família e Propriedade. Guia prático de prevenção contra invasões de terra: como tomar as medidas certas na hora certa. São Paulo: S.O.S. Fazendeiro, 1997.
}

Em Debat: Rev. Dig., ISSNe 1980-3532, Florianópolis, n. 5, p. 1-15, 2011. 
da Política Agrícola e Fundiária e da Reforma Agrária suas obras sobre a questão. ${ }^{8}$ Conforme uma destas, Reforma Agrária: terra prometida, favela rural ou kolkhozes, um parecer produzido pelo integrante do movimento contra a Reforma Agrária Atílio Guilherme Faoro, a difusão desse material teve grande repercussão em todo o país, o que levou a alguns setores da imprensa a "reconhecerem" que a TFP é "o principal elemento de articulação contra a Reforma Agrária" (1987, p. VII-VIII).

Nesta obra Faoro defende que a Reforma Agrária "prejudica muito mais gravemente ainda os trabalhadores rurais, do que os próprios fazendeiros. Se a estes ela 'mata', àqueles estraçalha!". O autor comenta que a "alta qualidade do [seu] trabalho foi objeto de elogioso comentário" do Prof. Sílvio Rodrigues, da Universidade de São Paulo, e "autor do famoso parecer sobre o direito que cabe aos fazendeiros de defesa à mão armada em caso de invasões de terra" (1987, p. 09).

Faoro já previa a dificuldade que seria barrar a Reforma Agrária na constituinte. Em legenda abaixo de uma fotografia do plenário do Congresso Nacional lotado, na sessão de abertura a Assembléia Nacional Constituinte, descreve o momento histórico:

\begin{abstract}
Abertura da Assembléia Nacional Constituinte, em fevereiro deste ano. Considerando a profundidade das alterações que a Reforma Agrária acarretará ao País, pesa sobre os ombros dos parlamentares constituintes a grave responsabilidade de deliberar sobre a matéria. Decidirão eles, em última análise, pela adoção ou rejeição de dispositivos constitucionais que garantam o direito de propriedade, tal como o consagrou nossa tradição jurídica, como um dos pilares da ordem econômica e social e uma das garantias das liberdades individuais (Faoro, 1987, p. 17).
\end{abstract}

Faoro explica que esse movimento, com motivação cristã, preocupa-se com a propaganda anticomunista. Nesse sentido realizou, na década de 1980, jornadas pelo interior de alguns estados do Brasil, com palestras, representações teatrais, projeções de filmes, audiovisuais etc (1987, p. 38).

Dez anos depois, em 1997, a entidade preocupava-se ainda com o tema da Reforma Agrária, agora com o foco em prevenir invasões de propriedades rurais por grupos de sem-terras. Por isso lançou o "Guia prático de prevenção contra invasões de terra: como tomar as medidas certas na hora certa". O panfleto foi escrito com base em dois pareceres dos juristas Silvio Rodrigues, professor da Universidade de São Paulo, e Orlando Gomes, professor da Universidade da Bahia. É um manual de como agir dentro

\footnotetext{
${ }^{8}$ Entre essas obras estão: Sou católico: posso ser contra a Reforma Agrária? (1981, 29 mil exemplares), A propriedade privada e a livre iniciativa no tufão agro-reformista (1985, 16 mil exemplares), ambas de autoria do Prof. Plínio Corrêa de Oliveira (parte doutrinária) e do Prof. Carlos Patrício del Campo (parte econômica), bem como o estudo No Brasil: a Reforma Agrária leva a miséria ao campo e à cidade - TFP informa, analisa, alerta (1986, 55 mil exemplares), de autoria do Prof. Plínio Corrêa de Oliveira", e a Reforma Agrária: terra prometida, favela rural ou kolkhozes, 1987.
}

Em Debat: Rev. Dig., ISSNe 1980-3532, Florianópolis, n. 5, p. 1-15, 2011. 
da legalidade para defesa da posse, inclusive com o uso de armas de fogo (Comissão de Estudos Agrários da Sociedade Brasileira de Defesa da Tradição, Família e Propriedade, 1997, p. 03).

A questão da legalidade está presente em orientações como esta: para "que você, fazendeiro, saiba como defender - legalmente - sua fazenda das invasões dos 'sem-terra', um movimento organizado, cujo caráter subversivo ninguém mais ignora. [...] Que, contra o subversivo MST, os proprietários rurais saibam reagir segundo a LEI, dentro da ORDEM". (1997, p. 08).

Destaca-se ainda no panfleto, outra orientação neste sentido:

Defendendo legalmente o que é seu, você estará colaborando para evitar a violência, e concorrendo para restabelecer a paz no campo. Agindo segundo o que sugere este GUIA, você poderá evitar a invasão de sua fazendo. Instrua sua família e seus empregados sobre como utilizá-lo. Garanta a inviolabilidade de sua propriedade (1997, p. 04).

É interessante perceber que para os autores deste documento, a paz no campo faz-se com o conflito, inclusive armado, contra os invasores. Seria o uso do direito ao desforço privado e imediato, constante no artigo 502, do Código Civil de 1916. Poderia chegar-se ao uso de armas se o seu emprego for indispensável à manutenção ou à restituição da posse, conforme o parecer dos juristas antes referidos. Assim, "se uma resistência pacífica, cercas de arame, barreiras de homens, disparos de advertência para o ar, não bastarem e, pior, se as autoridades constituídas cruzarem os braços, a própria lei diz que é legal e legítima a resistência armada" (1997, p. 29-37).

Assim, fica-se com o testemunho dos próprios agentes contra a Reforma Agrária, do seu caráter autoritário e a busca desastrada em amparar suas ações na legalidade, sob o amparo das opiniões de "grandes juristas".

\section{A política e o estado de exceção}

Passa-se a analisar a possibilidade de estes fatos colaborarem com a tese de Giorgio Agamben, de que estaríamos vivendo a "decadência da democracia moderna e o seu progressivo convergir com os estados totalitários nas sociedades pós-democráticas espetaculares", já ressaltada por Tocqueville e Debord. Estamos diante da tese de uma íntima solidariedade entre democracia e totalitarismo, no sentido histórico-filosófico, pois em termos de história esses permanecem muito bem demarcados (Agamben, 2002, p. 17-18). 
Para Agamben, uma vez reunida a constituinte, é preciso ter como pressupostos fatores que influenciam diretamente suas decisões, tais quais: a definição da soberania, o problema dos limites e da estrutura originária da "estatalidade" (2002, p. 19).

A assembléia brasileira em 1987 estava bastante comprometida em relação ao seu poder constituinte. Tanto no poder legislativo quanto na representação do executivo que assumiria o poder. Houve um desrespeito consciente ao regramento da constituição anterior, que previa a realização de eleição própria para deputados e senadores constituintes, sendo que estes foram eleitos por voto direto para a legislatura sem poderes para fazer a nova constituição e mesmo assim o fizeram. Também, o executivo federal que assumiria o período pós-ditatorial não foi eleito por voto direto, mas pelo do mesmo parlamento.

Conforme Agamben, "a constituição se pressupõe como poder constituinte”, o paradoxo da soberania mostra-se à luz com o problema da distinção entre o poder constituinte e o poder constituído. Inspirado nas palavras de Walter Benjamin define que a relação entre esses poderes estava como para violência que põe o direito e violência que o conserva (2002, p. 47-48).

Ademais dos questionamentos sobre o poder constituinte, diz-se que o resultado do poder constituído pela constituição de 1988, no tocante à política agrária, foi colocado a partir de uma "força bruta", no sentido empregado por Freud, isto é, na preservação de interesses individuais em detrimento da coletividade.

Foram postos por uma violência absolutamente 'fora' e 'além' do direito. Para Agamben, esta violência poderia quebrar a dialética entre violência que funda o direito e violência que o conserva. O que não pode ser tolerado de modo algum pelo direito, "o que sente como uma ameaça contra a qual é impossível transigir, é a existência de uma violência fora do direito; não porque os fins de tal violência sejam incompatíveis com o direito, mas 'pelo simples fato de sua existência fora do direito"' (2002, p. 84-85).

Essa violência fora do direito está muito bem configurada nas estratégias da UDR e da TFP, no tocante à atuação para "convencimento" dos parlamentares e na repreensão privada às invasões de propriedade. Como ensina Agamben, “o caráter próprio dessa violência é que ela não põe nem conserva o direito, mas o depõe e inaugura, assim, uma nova época histórica”. Trata-se justamente da exceção (2002, p. $85)$. 
Outro conceito importante é o da biopolítica, que Michel Foucault define diferenciando-o do poder soberano do velho Estado territorial, mediante o cruzamento de duas fórmulas simétricas:

Fazer morrer e deixar viver resume a marca do velho poder soberano, que se exerce, sobretudo, como direito de matar; fazer viver e deixar morrer é a marca do biopoder, transformando a estatização do biológico e do cuidado com a vida no seu próprio objetivo primário (Foucault apud Agamben, 2008, p. 155).

Essa definição pode encaixar-se no conjunto dos fatos e dados apresentados sobre os conflitos no campo no Brasil. Porém, com a ressalva de que o referido "deixar morrer" implica numa complexidade dificilmente demonstrável a partir desses exemplos.

Por outro lado, fica-se com a idéia de Agamben que "a política sofreu um eclipse duradouro porque foi contaminada pelo direito, concebendo-se a si mesma, no melhor dos casos, como poder constituinte (isto é, violência que põe o direito), quando não se reduz simplesmente a poder de negociar com o direito". Porém, ocorre o contrário, verdadeiramente política é apenas aquela ação que corta o nexo entre violência e direito, “e somente a partir do espaço que assim se abre, é que será possível colocar a questão a respeito de um eventual uso do direito após a desativação do dispositivo que, no estado de exceção, o ligava à vida" (2004, p. 133).

Trata-se de recuperar esse sentido da política, para instaurar o direito. Isto porque o Estado de exceção é aquele que depõe o direito (força que ainda não foi capturada pelo direito). Inclusive porque o código social é o mais rígido, totalitário, do que o daqueles que mandam. Para contrapor-lhe é preciso um ato, que é um limite. A Lei é que permite esta mediação, porque restabelece a fronteira do humano, que não pode ser ultrapassado. Estabelece o que é comum, próprio do humano, possibilita a ação. A norma, como a "constituição", no tocante à reforma agrária, apenas leva a uma relação imediata. Um negócio entre as partes pode ser norma como disciplina. A Lei, que é o limite, não é imposta, é trabalhada, permite várias "inscrituras".

\section{Conclusão}

A proposta é a atuação de atores políticos democráticos da sociedade civil na esfera pública. Um trabalho de cultura, no sentido freudiano, da produção de sujeitos e 
de obras na "tessitura" das relações sociais - vêm com a lei - que é um trabalho constante.

Não se pode abdicar da capacidade de pensar. Autoriza-se pela omissão o autoritarismo com aqueles que estão sendo penalizados não por seus atos, mas simplesmente por serem o que são, como os sem-terra. Alimenta-se a máquina letal que representa toda forma de regime totalitário, se a aparência dessa truculência estatal contra aqueles que lutam por reforma agrária não anuncia com alarde esta constatação. Imerso no caldo da perversidade da repressão está a semente da intolerância e da exceção.

A questão fundamental é que uma geração faça a educação da outra. Pois, como ensina Dany-Robert Dufour, desaparecendo o motivo geracional, não há mais disciplina e, como não há mais disciplina, não há mais educação (Dufour, 2006, p. 141). Essa questão tem que ser valorizada, justamente para que o direito passe a cumprir alguma função educativa, ao menos a pretensa função de cidadania ativa.

O estudo do poder constituinte a partir de visões históricas de períodos de transição de regimes ditatoriais para democráticos representa um grande desafio para a filosofia do direito. Em primeiro lugar, é preciso partir da busca por diferentes versões, que possam aproximar o pesquisador da realidade. Em seguida, é fundamental estar alerta para os meandros das narrativas históricas, repletas de sentidos contraditórios e apaixonados. Por isso é fundamental partir da subjetividade, que reconhece a influência do sujeito no espaço pesquisado, podendo assim dissecá-lo e distanciá-lo para uma análise mais objetiva.

Deixa-se aqui uma contribuição para a recuperação da memória da história recente de nosso país, especialmente no que tange à Assembléia Nacional Constituinte e a tão comemorada transição democrática. A partir de agora, convoca-se a juventude para a crítica e a tomada de consciência dos abusos cometidos por atores antidemocráticos, que continuam presentes em todas as escalas de poder em nossa sociedade ainda hoje. Principalmente, desafia-se ao repensar da responsabilização desses sujeitos por seus atos funestos, requisito fundamental para a construção do Estado constitucional brasileiro.

\section{Referências Bibliográficas}

AGAMBEN, Giorgio. Homo Sacer: o poder soberano e a vida nua I. Belo Horizonte: Ediufmg, 2002. 
AGAMBEN, Giorgio. Estado de exceção. São Paulo: Boitempo, 2004.

2008.

O que resta de Auschwitz: o arquivo e a testemunha. São Paulo: Boitempo,

ALFONSIN, Jacques Távora. $O$ acesso à terra como conteúdo de direitos humanos fundamentais à alimentação e à moradia. Porto Alegre: Safe, 2003.

ARENDT, Hannah. Responsabilidade e julgamento. São Paulo: Companhia das Letras, 2004.

COMISSÃO DE ESTUDOS AGRÁRIOS DA SOCIEDADE BRASILEIRA DE

DEFESA DA TRADIÇÃO, FAMÍLIA E PROPRIEDADE. Guia prático de prevenção contra invasões de terra: como tomar as medidas certas na hora certa. São Paulo: S.O.S. Fazendeiro, 1997.

COMISSÃO PASTORAL DA TERRA. Conflitos no campo Brasil 1997. Passo Fundo: Pe. Berthier, 1998.

DUFOUR, Dany-Robert. A arte de reduzir as cabeças. Rio de Janeiro: Companhia de Freud, 2006.

FAORO, Atilio Guilherme. Reforma Agrária: terra prometida, favela rural ou 'kolkhozes'?. São Paulo: Vera Cruz, 1987.

FREUD, Sigmund. O mal-estar na civilização. Rio de Janeiro: Imago, 1997.

GOMES DA SILVA, José. Buraco negro: a Reforma Agrária na Constituinte de 198788. Rio de Janeiro: Paz e Terra, 1989.

PILATI, Adriano. Marchas de uma contramarcha: transição, UDR e Constituinte. Dissertação - Curso de Mestrado em Direito. Pontifícia Universidade Católica do Rio de Janeiro, Rio de Janeiro, 1988.

PRESSBURGER, Miguel. A propriedade da terra na constituição. 6. ed. Rio de Janeiro: AJUP/FASE, 1986. Coleção "Socializando Conhecimento" n. 2. 